\title{
ELECTRONIC HEALTH RECORD USAGE IN SOUTHERN US STATES
}

\author{
Myungjae Kwak, Middle Georgia State University, myungjae.kwak@mga.edu \\ John Girard, Middle Georgia State University,john.girard@mga.edu
}

\begin{abstract}
The purpose of this project was to review the electronic health record technology usage in the southern US states to determine if anomalies exist by state or by year. The analysis of secondary data collected and disseminated by U.S. Department of Health and Human Services (HHS)'s Office of the National Coordinator for Health IT revealed several anomalies that warrant further investigation. The major finding was that some statistically significant differences existed, in consecutive years, for demonstrated use of electronic heath record technology by some health care professionals. The second interesting finding surrounds the demonstrated use by some segments of the healthcare community. Although no statically significant difference was discovered by health professionals in general, we did discover some differences in the nurse practitioner and health physician assistance communities of some states. We anticipate these findings will be the catalyst for future research to answer the question why the differences existed.
\end{abstract}

Keywords: Information Technology (IT), health, incentives

\section{INTRODUCTION}

The demonstrated meaningful use of certified electronic health record technology by office-based health professionals in the USA has increased from $31 \%$ in 2013 to $46 \%$ in 2015 . This increase is due, in a large part, to incentive programs operated at the national and state levels. The aim of the paper is to review the usage of Certified Electronic Health Record Technology (CERHT) in the southern US states to determine if anomalies exist by state or by year. This foundational research will provide a platform to launch additional research in the future.

\section{LITERATURE REVIEW}

In 2009, U.S. Congress and the Obama administration provided a transformative opportunity to the health care community with regard to adopting Electronic Health Records or EHR (Blumenthal \& Tavenner, 2010). The Health Information Technology for Economic and Clinical Health Act (HITECH) authorized financial incentive through Medicare and Medicaid to eligible clinicians and hospitals when they use EHRs to achieve specified improvements in their care delivery (Blumenthal \& Tavenner, 2010). According the HITECH Act, the Medicare and Medicaid EHR Incentive Programs (Centers for Medicare \& Medicaid Services, 2016) can provide incentive financial support to eligible professionals (EPs) and eligible hospitals if they adopt, implement, upgrade, or demonstrate "meaningful use" of certified EHR technology (Miller, Noonan, Fiks, \& Lehmann, 2015).

In the Medicare and Medicaid EHR Incentive Programs, Medicare EPs include doctors of medicine or osteopathy, doctors of dental surgery or dental medicine, doctors of podiatric medicine, doctors of optometry, and chiropractors. Medicaid EPs are physicians, nurse practitioners, certified nurse-midwives, dentists, and Physician Assistants (PAs) in PA-led Federally Qualified Health Centers (FQHC) or Rural Health Clinics (RHC). Medicare eligible hospitals are ones that are paid under the hospital inpatient perspective payment system, Critical Access Hospitals (CAHs), and Medicare Advantage (MA) Hospitals. Medicaid eligible hospitals are acute care hospitals (including CAHs) with at least $10 \%$ Medicaid patient volume and children's hospitals (no Medicaid volume required). EPs can receive incentive payments as much as $\$ 44,000$ through the Medicare EHR Incentive Program, or as much as $\$ 63,750$ through the Medicaid EHR Incentive Program. Eligible hospitals can receive some \$2 million or more through the two incentive programs. 


\section{Issues in Information Systems}

Volume 17, Issue II, pp. 1-8, 2016

For health care professionals and hospitals to receive the incentive payments, they have to demonstrate that their EHR systems meet a set of meaningful use objectives in three different stages. If providers fail to attest to meaningful use within certain period, they are subject to penalties (Wright, Feblowitz, Samal, McCoy, \& Sittig, 2014). The "meaningful use" means that health care providers should use EHRs to achieve significant improvement in their health care processes and outcomes, meeting certain measurement thresholds in three different stages. (Blumenthal \& Tavenner, 2010). The Centers for Medicare and Medicaid Services (CMS) has established the goals and requirements of the three meaningful use stages (HealthIT.gov, 2016). Meaningful Use Stage One, launched in 2011, focuses on proper data capture and data sharing using EHR technology and requires health care providers to meet a set of core and public health objectives and measures. Meaningful Use Stage Two, which began in 2014, emphasizes advanced clinical processes that require new objectives and higher thresholds. Meaningful Use Stage Three, which is scheduled to start in 2017, stresses improved outcomes (HealthIT.gov, 2016).

It seems that the EHR incentive programs are welcomed among health care professionals and hospitals. In 2013, it is reported that $69 \%$ of office-based physicians have already participated in or planned to apply for the incentive programs (Hsiao \& Hing, 2014). About 13\% of all office-based physicians both intended to participate in the incentive programs and already had EHR systems that can satisfy the objectives and measures of the Meaningful Use Stage Two (Hsiao \& Hing, 2014). Hsiao and Hing's report also shows that from 2010 to 2013, the percentage of physicians who adopted EHR systems that can support the Meaningful Use Stage Two objectives increased significantly. In the meantime, Wright et al.'s study shows that over 237,000 eligible providers have registered for the Medicare incentive program and successfully attested to the Meaningful Use Stage 1 by May 31, 2013 (Wright, Feblowitz, Samal, McCoy, \& Sittig, 2014). Moreover, many providers significantly exceeded the Meaningful Use thresholds in Stage 1 (Wright, Feblowitz, Samal, McCoy, \& Sittig, 2014). Therefore, Wright et al. argues that since providers are successfully attesting to the CMS requirements and often exceeding the thresholds, program's requirements should be raised in future years (Wright, Feblowitz, Samal, McCoy, \& Sittig, 2014).

Although the incentive programs are recognized as a transformational opportunity for EHRs' adoption and advancement, there exist various obstacles and challenges since technology is infused into what has been a historically manual process (Heisey-Grove, Danehy, Consolazio, Lynch, \& Mostashari, 2014). To track challenges to EHR adoption and meaningful use, Heisey-Grove et al. analyzed nationwide data including 19,000 issues related to the incentive programs from 43,000 health care providers. Their analysis shows that the most common issues across all cohorts are provider engagement and administrative issues. It also indicates that while the most challenging meaningful use measure in Stage 1 was the clinical summaries measure, meaningful use measure challenges varied by practice setting (Heisey-Grove, Danehy, Consolazio, Lynch, \& Mostashari, 2014).

In the same sense, Miller et al.'s study shows that pediatricians face unique obstacles to participation in the incentive programs (Miller, Noonan, Fiks, \& Lehmann, 2015). They argued that there have been problems with EHR functionality to support pediatric care and the meaningful use incentives are not properly aligned with child health priorities. They argued that the current structure of the incentive programs put pediatricians at a disadvantage compared with clinicians caring for adults, leading to wide variability in pediatrician participation in the program across states (Miller, Noonan, Fiks, \& Lehmann, 2015). While a national average participation rate is little less than $20 \%$ in 2012, pediatrician participation varied significantly across states, from little less than $10 \%$ in New Jersey, Georgia, and Hawaii to nearly $70 \%$ in North Dakota (Miller, Noonan, Fiks, \& Lehmann, 2015). Therefore, they argue that specific solutions to support effective pediatric EHR implementation across all states are necessary.

In the meantime, Furukawa et al.'s study suggests that although EHR adoption continues to propagate, policies to support health information exchange and patient engagement will require ongoing attention (Furukawa, et al., 2014). Furukawa et al.'s data shows that in 2013, 78\% of office-based physicians had adopted some type of EHRs, and $48 \%$ had the capabilities required for a basic EHR system. However, they also found that there is a large gap among of physicians with different settings. Especially, physicians in solo practices and non-primary care specialties are lagging behind others. Moreover, only $14 \%$ of physicians are sharing health data with other providers, $30 \%$ have regularly used secure messaging tools with patients, and $24 \%$ routinely provided patients with the capability to view online, download, or transmit their health record (Furukawa, et al., 2014). 


\section{RESEARCH METHODOLOGY}

All of the data used in the project is from the Health IT Dashboard which is a US Government Open Government initiative developed and maintained by the U.S. Department of Health and Human Services (HHS)'s Office of the National Coordinator for Health IT (ONC). This study focused specifically on the South of the USA; one of the four geographic segments specified by ONC. The South includes the following states: Alabama (AL), Arkansas (AR), Florida (FL), Georgia (GA), Kentucky (KY), Louisiana (LA), Mississippi (MS), North Carolina (NC), Oklahoma (OK), South Carolina (SC), Tennessee (TN), Texas (TX), Virginia (VA) and West Virginia (WV).

This project is focused on four key variables derived from the Centers for Medicare \& Medicaid Services (CMS) EHR Incentive Programs data by the ONC. Specifically, the research is focused on the percentage of all officebased medical doctors, doctors of osteopathy, nurse practitioners, and physician assistants that have demonstrated meaningful use CEHRT. This demonstration of meaningful use may be achieved through either the Medicare or Medicaid EHR Incentive Programs; however, there are some caveats as outline below.

The data has been derived for 2013, 2014 and 2015; however, it should be noted that 2013 and 2014 represented the yearend (December) whereas the 2015 data is from April. The remaining three variables are subsets of the population: physicians, physician assistants, and nurse practitioners that have demonstrated meaningful use of CEHRT. The primary interest lies with differences between states over the three-year period and year-on-year differences between two consecutive years. The four variables under review are described below.

Health Professionals CEHRT User. The first variable, Health Professional CEHRT User, is percentage of physicians, physician assistants, and nurse practitioners that have demonstrated meaningful use of CEHRT. This only includes medical doctors, doctors of osteopathy, nurse practitioners, and physician assistants practicing in ambulatory care settings. The means are calculated by using data from the CMS EHR Incentive Programs that is divided by an approximation of the total population derived by the ONC. Although this is an estimate, the method is consistent for all subsets and is the best available approximation. The variable's full name is Percentage of Physicians, Physician Assistants, and Nurse Practitioners that have Demonstrated Meaningful Use of CEHRT. This variable leads to the first two hypotheses:

H1: The percentage of health professionals in some Southern states that have demonstrated meaningful use of CEHRT is significantly lower level than other states.

H2: In some years, the increase in the percentage of health professionals in Southern states that have demonstrated meaningful use of CEHRT is significantly lower than other years.

Physicians CEHRT User. The variable full name is percentage of physicians that have demonstrated meaningful use of CEHRT and is the percentage of all office-based medical doctors and doctors of osteopathy that have demonstrated meaningful use of CEHRT. This excludes non-MD/DO practitioners (chiropractors, dentists, optometrists, and podiatrists) who participated in the incentive programs. The dataset incudes physicians that demonstrated meaningful use through either the Medicare or Medicaid EHR Incentive Programs. This variable leads to the second two hypotheses:

H3: The percentage of physicians in some Southern states that have demonstrated meaningful use of CEHRT is significantly lower level than other states.

H4: In some years the increase in the percentage of physicians in Southern states that have demonstrated meaningful use of CEHRT is significantly lower than other years.

Physicians CEHRT User. The variable full name is percentage of nurse practitioners that have demonstrated meaningful use of CEHRT and is percentage of all office-based nurse practitioners that have demonstrated 
meaningful use of CEHRT. The data set only includes nurse practitioners that participated in the Medicaid EHR Incentive Program. This variable leads to two hypotheses:

H5: The percentage of nurse practitioners in some Southern states that have demonstrated meaningful use of CEHRT is significantly lower level than other states.

H6: In some years, the increase in the percentage of nurse practitioners in Southern states that have demonstrated meaningful use of CEHRT is significantly lower than other years.

Physician Assistants CEHRT User. The variable full name is percentage of physician assistants that have demonstrated meaningful use of CEHRT and is percentage of all office-based physician assistants that have demonstrated meaningful use of CEHRT. The dataset only includes physician assistants from Federal Qualified Health Centers (FQHCs) that participate in the Medicaid Program. This variable leads to the last two hypotheses:

H7: The percentage of physician assistants in some Southern states that have demonstrated meaningful use of CEHRT is significantly lower level than other states.

H8: In some years, the increase in the percentage of physician assistants in Southern states that have demonstrated meaningful use of CEHRT is significantly lower than other years.

\section{RESULTS}

The same procedure was followed for each of the eight hypotheses. First, the data for the states under review was extracted from CMS' EHR Incentive Programs dataset. Next, the data was converted to a chart to conduct a visually review of the individual states by year. Once the visual review was complete, a one-way ANOVA was used to test for differences among 14 states and for the three years under review $(2013-2015)$. If a difference was identified, then post-hoc comparison using the Tukey HSD test was conducted to determine which consecutive years or states showed the difference.

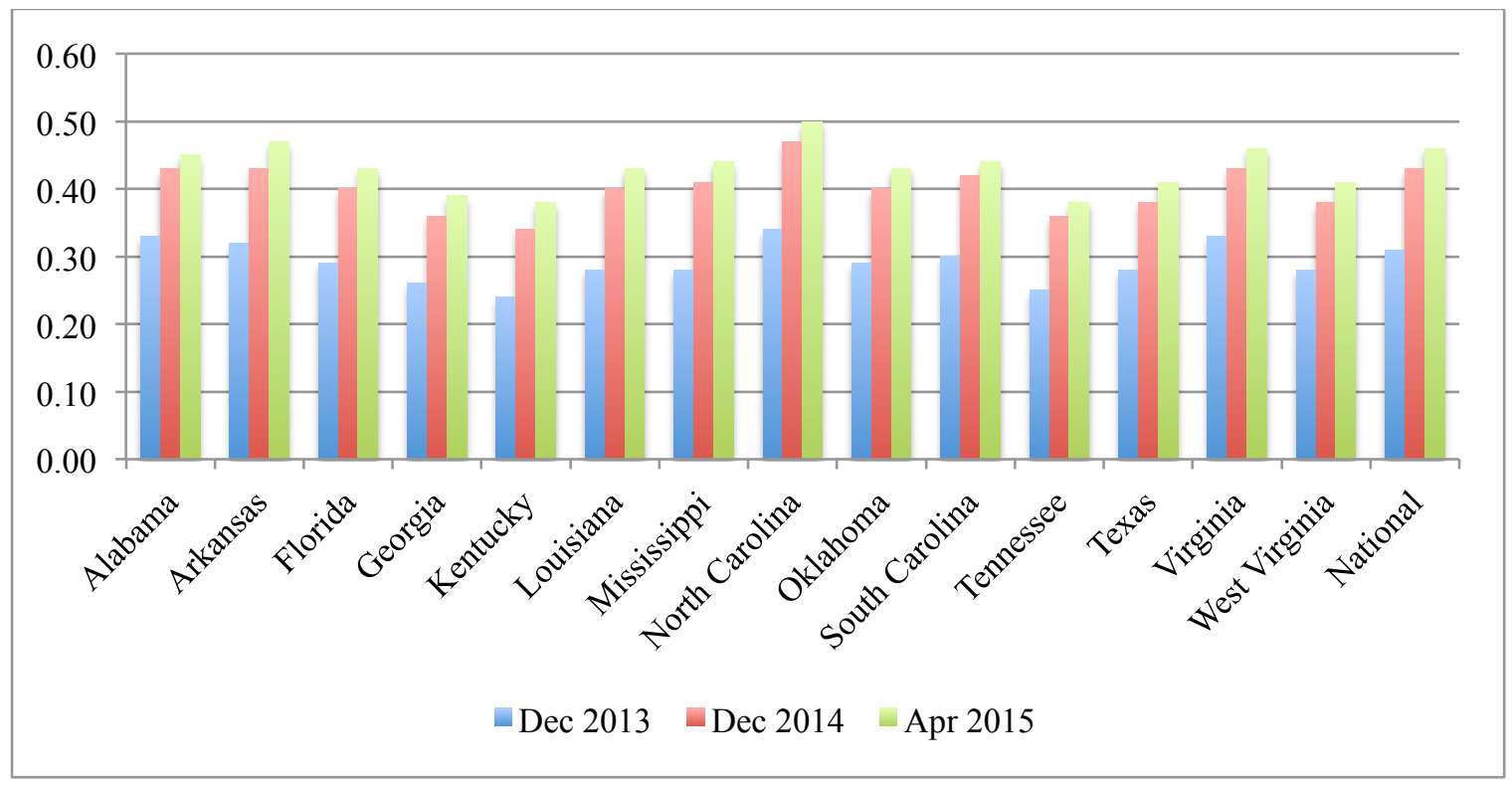

Figure 1. Health Professionals CEHRT Users 
H1: Health Professional by State. A one-way ANOVA was used to test for demonstrated use percentages among the 14 states. Usage percentages did not differ significantly at the $\mathrm{p}<.05$ level across the 14 states, $F(13,28)=$ $0.51, p=0.840$.

H2: Health Professional by Year. A one-way ANOVA was used to test for demonstrated use percentages over the three-year period $(2013-2015)$. Usage percentages did differ significantly at the $\mathrm{p}<.05$ level for the three years, $F(2,39)=68.18, p=0.000$. Post-hoc comparison using the Tukey HSD test indicated that the mean for 2013 $(\mathrm{M}=0.29, \mathrm{SD}=0.030)$ was significantly different than $2014(\mathrm{M}=0.40, \mathrm{SD}=0.035)$.

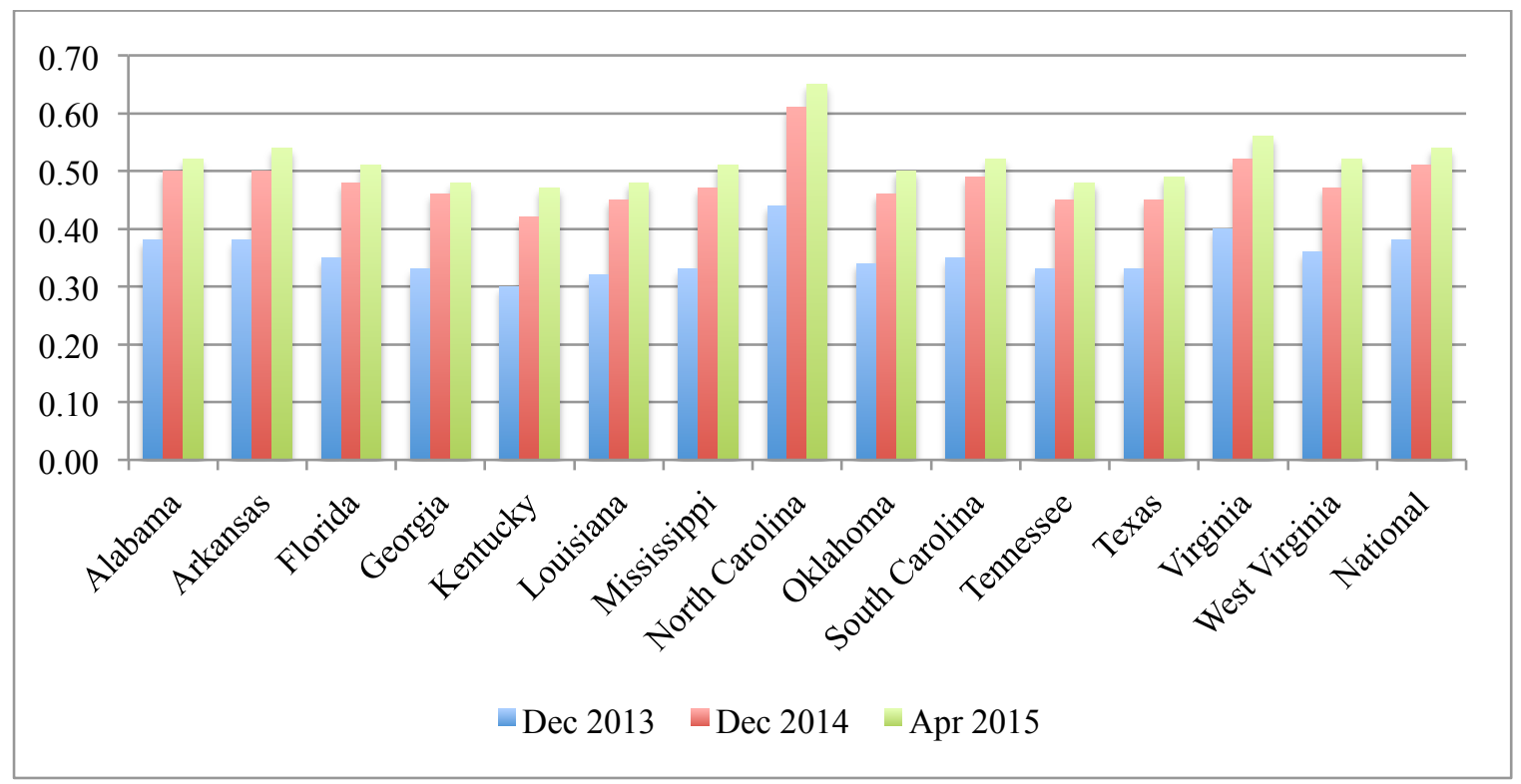

Figure 2. Physicians CEHRT Users

H3: Physicians by State. A one-way ANOVA was used to test for demonstrated use percentages among the 14 states. Usage percentages did not differ significantly at the $\mathrm{p}<.05$ level across the 14 states, $F(13,28)=0.71, p=$ 0.737 .

H4: Physicians by Year. A one-way ANOVA was used to test for demonstrated use percentages over the threeyear period $(2013-2015)$. Usage percentages did differ significantly at the $\mathrm{p}<.05$ level for the three years, $F(2,39)$ $=56.32, p=0.000$. Post-hoc comparison using the Tukey HSD test indicated that the mean for $2013(\mathrm{M}=0.35$, SD $=0.037)$ was significantly different than $2014(\mathrm{M}=0.48, \mathrm{SD}=0.045)$. 


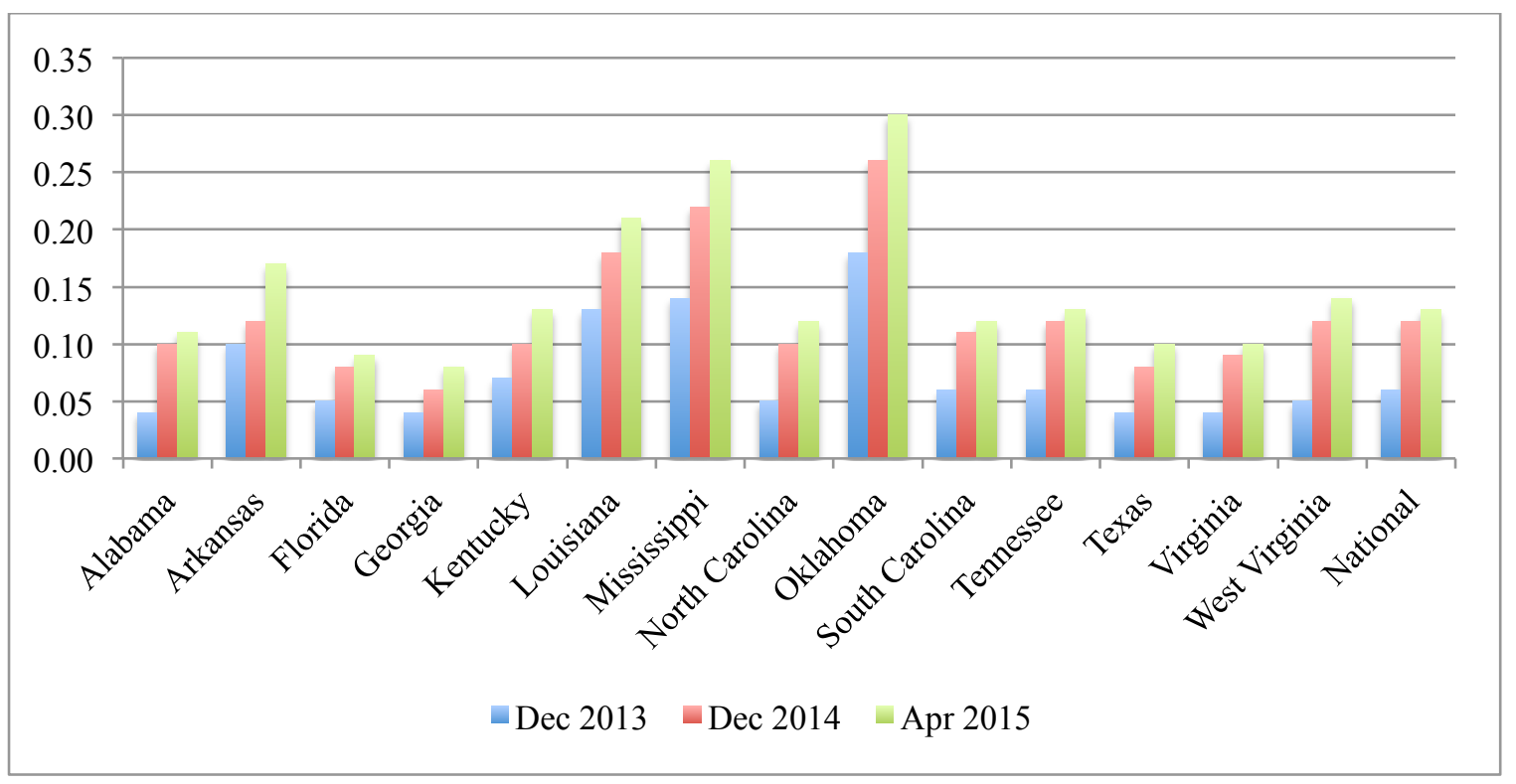

Figure 3. Nurse Practitioners CEHRT Users

H5: Nurse Practitioners by State. A one-way ANOVA was used to test for demonstrated use percentages among the 14 states. Usage percentages did differ significantly at the $\mathrm{p}<.05$ level for the states, $F(13,28)=5.97, p=0.00$. Post-hoc comparison using the Tukey HSD test indicated that significant differences between:

- $\quad$ Alabama $(\mathrm{M}=0.08, \mathrm{SD}=0.038)$ and Mississippi $(\mathrm{M}=0.21, \mathrm{SD}=0.061)$

- $\quad$ Alabama $(\mathrm{M}=0.08, \mathrm{SD}=0.038)$ and Oklahoma $(\mathrm{M}=0.25, \mathrm{SD}=0.061)$

- Florida $(\mathrm{M}=0.07, \mathrm{SD}=0.021)$ and Mississippi $(\mathrm{M}=0.21, \mathrm{SD}=0.061)$

- Florida $(\mathrm{M}=0.07, \mathrm{SD}=0.021)$ and Oklahoma $(\mathrm{M}=0.25, \mathrm{SD}=0.061)$

- $\quad$ Georgia $(\mathrm{M}=0.06, \mathrm{SD}=0.020)$ and Mississippi $(\mathrm{M}=0.21, \mathrm{SD}=0.061)$

- Georgia $(\mathrm{M}=0.06, \mathrm{SD}=0.020)$ and Oklahoma $(\mathrm{M}=0.25, \mathrm{SD}=0.061)$

- $\quad$ Kentucky $(\mathrm{M}=0.10, \mathrm{SD}=0.030)$ and Oklahoma $(\mathrm{M}=0.25, \mathrm{SD}=0.061)$

- Mississippi $(\mathrm{M}=0.21, \mathrm{SD}=0.061)$ and Texas $(\mathrm{M}=0.07, \mathrm{SD}=0.021)$

- $\quad$ Mississippi $(\mathrm{M}=0.21, \mathrm{SD}=0.061)$ and Virginia $(\mathrm{M}=0.08, \mathrm{SD}=0.032)$

- $\quad$ North Carolina $(\mathrm{M}=0.09, \mathrm{SD}=0.036)$ and Oklahoma $(\mathrm{M}=0.25, \mathrm{SD}=0.061)$

- Oklahoma $(\mathrm{M}=0.08, \mathrm{SD}=0.045)$ and South Carolina $(\mathrm{M}=0.10, \mathrm{SD}=0.032)$

- Oklahoma $(\mathrm{M}=0.25, \mathrm{SD}=0.061)$ and Tennessee $(\mathrm{M}=0.10, \mathrm{SD}=0.038)$

- Oklahoma $(\mathrm{M}=0.25, \mathrm{SD}=0.061)$ and Texas $(\mathrm{M}=0.07, \mathrm{SD}=0.021)$

- Oklahoma $(\mathrm{M}=0.25, \mathrm{SD}=0.061)$ and West Virginia $(\mathrm{M}=0.10, \mathrm{SD}=0.047)$

H6: Nurse Practitioners by Year. A one-way ANOVA was used to test for demonstrated use percentages over the three-year period $(2013-2015)$. Usage percentages did differ significantly at the $\mathrm{p}<.05$ level for the three years, $F(2,39)=5.97, p=0.01$. Post-hoc comparison using the Tukey HSD test indicated that the mean for 2013 $(\mathrm{M}=0.08, \mathrm{SD}=0.045)$ was significantly different than $2015(\mathrm{M}=0.15, \mathrm{SD}=0.066)$. Given that, this is two nonconsecutive years it is not relevant to this project. 


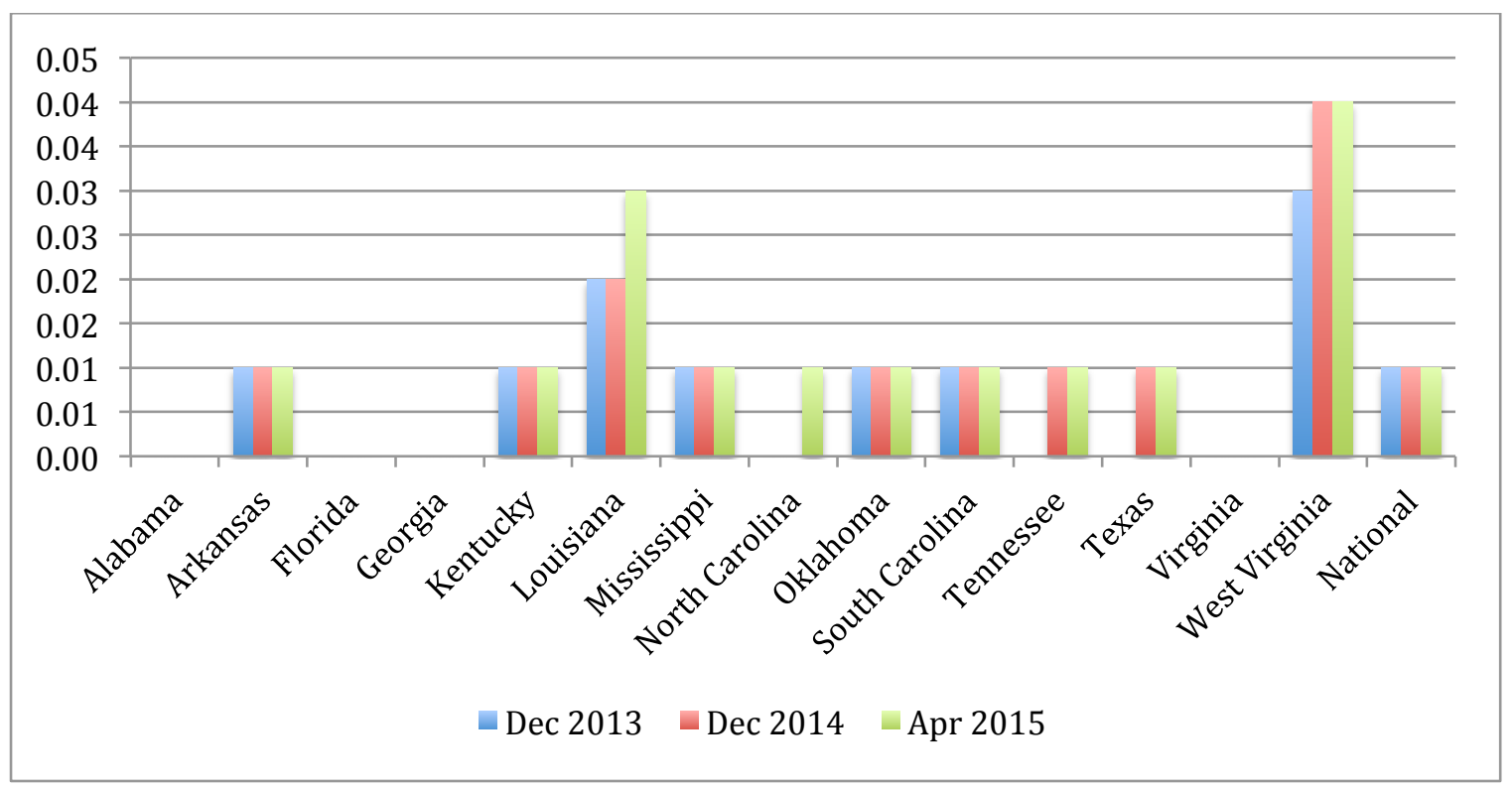

Figure 4. Physician Assistant CEHRT Users

H7: Physician Assistants by State. A one-way ANOVA was used to test for demonstrated use percentages among the 14 states. Usage percentages did differ significantly at the $\mathrm{p}<.05$ level for the states, $F(13,28)=26.03, p=0.00$. Post-hoc comparison using the Tukey HSD test indicated that significant differences between both Louisiana and every other state as well as West Virginia and every other state.

H8: Physician Assistants by Year. A one-way ANOVA was used to test for demonstrated use percentages over the three-year period $(2013-2015)$. Usage percentages did not differ significantly at the $p<.05$ level for the three years, $F(2,39)=0.41, p=0.413$.

\section{SUMMARY}

The aim of this foundational research was to review the usage of certified electronic health record technology in the southern US states to determine if anomalies exist by state or by year. The analysis of secondary data collected and disseminated by U.S. Department of Health and Human Services (HHS)'s Office of the National Coordinator for Health IT revealed several anomalies that warrant further investigation. The major finding was that some statistically significant differences existed, in consecutive years, for demonstrated use of electronic heath record technology by some health care professionals. The second interesting finding surrounds the demonstrated use by some segments of the healthcare community. Although no statistically significant difference was discovered by health professionals in general, we did discover some differences in the nurse practitioner and health physician assistance communities of some states. We anticipate these findings will be the catalyst for future research to answer the question why the differences existed.

The major limitation of research is the available data. At present, just three years of data is available. As more data becomes available in the coming years, we anticipate revisiting the research with a view to strengthening the findings. 


\section{Issues in Information Systems}

Volume 17, Issue II, pp. 1-8, 2016

\section{REFERENCES}

Blumenthal, D., \& Tavenner, M. (2010). The "meaningful use" regulation for electronic health records. New England Journal of Medicine, 363(6), 501-504.

Centers for Medicare \& Medicaid Services. (2016, 1 5). Electronic Health Records (EHR) Incentive Programs. Retrieved from https://www.cms.gov/Regulations-and-

Guidance/Legislation/EHRIncentivePrograms/index.html?redirect=/EHRIncentivePrograms/

Furukawa, M. F., King, J., Patel, V., Hsiao, C. J., Adler-Milstein, J., \& Jha, A. K. (2014). Despite substantial progress in EHR adoption, health information exchange and patient engagement remain low in office settings. Health Affairs, 33(9), 1672-1679.

HealthIT.gov. (2016). Meaningful Use Definition \& Objectives. Retrieved from https://www.healthit.gov/providersprofessionals/meaningful-use-definition-objectives

Heisey-Grove, D., Danehy, L. N., Consolazio, M., Lynch, K., \& Mostashari, F. (2014). A national study of challenges to electronic health record adoption and meaningful use. Medical Care, 52(2), 144-148.

Hsiao, C. J., \& Hing, E. (2014). Use and Characteristics of Electronic Health Record Systems Among Office-based Physician Practices: United States, 2001-2013. US Department of Health and Human Services, Centers for Disease Control and Prevention, National Center for Health Statistics.

Medicare \& Medicaid EHR Incentive Programs Measures (2015). Office of the National Coordinator for Health Information Technology. Available online at:

http://dashboard.healthit.gov/datadashboard/documentation/cms-ehr-incentive-program-measuresdocumentation.php

Miller, D., Noonan, K., Fiks, A. G., \& Lehmann, C. U. (2015). Increasing pediatrician participation in EHR incentive programs. Pediatrics, 135(1), e1-e4.

Wright, A., Feblowitz, J., Samal, L., McCoy, A. B., \& Sittig, D. F. (2014). The Medicare Electronic Health Record Incentive Program: provider performance on core and menu measures. Health Services Research, 49(1pt2), 325-346. 